\title{
Three-dimensional printing of models for surgical planning in patients with primary cardiac tumors
}

\author{
Daniel Schmauss, MD, ${ }^{\mathrm{a}}$ Nicolas Gerber, MSc, ${ }^{\mathrm{b}}$ and Ralf Sodian, $\mathrm{MD}^{\mathrm{a}}$
}

Primary cardiac tumors are rare and mostly benign but have the potential to cause significant morbidity. Surgical treatment is suggested when symptoms or hemodynamic impairment is present. Deciding which surgical strategy (total tumor resection, partial tumor resection, or heart transplant) is best for the individual patient is often difficult because of insufficient imaging. We are therefore exploring the impact of using rapid-prototyping techniques for decision making, surgical planning, and intraoperative orientation for surgical treatment in patients with primary cardiac tumors.

\section{TECHNIQUE AND RESULTS}

In a 43-year-old female patient with a right-ventricular primary cardiac tumor, the diagnosis was suggested by ultrasonography and magnetic resonance imaging, which showed an intrapericardial mass on the right ventricular wall consistent with a cardiac fibroma. A computed tomographically guided biopsy of the tumor confirmed this suspicion.

From data derived from computed tomographic scans, we were able to fabricate 3-dimensional replicas of the cardiac anatomy. In our models, the tumor tissue was colored differently from the cardiac tissue because of its different density, making it possible to delimit the pathologic tissue exactly (Figures 1 and 2). In addition, it was possible to sterilize the model and take it to the operating room for better intraoperative orientation.

On the basis of the exact anatomic understanding thus obtained, we determined that an excision in toto would be the best therapeutic option for our patient because of the only moderate infiltration of the tumor into the right ventricular wall. Figure 3 shows the intraoperative findings.

\section{DISCUSSION}

Stereolithography has been shown to be a useful tool in pediatric and adult cardiac surgery and other disciplines ${ }^{1-3}$

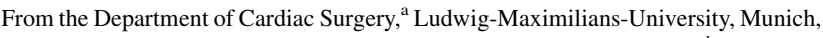
Germany; and the Institute for Surgical Technology and Biomechanics, ${ }^{\mathrm{b}}$ University of Bern, Bern, Switzerland.

Disclosures: Authors have nothing to disclose with regard to commercial support.

Received for publication Oct 17, 2012; revisions received Nov 15, 2012; accepted for publication Dec 10, 2012; available ahead of print Jan 10, 2013.

Address for reprints: Daniel Schmauss, MD, Reitmorstrasse 12, 80538 München,

Bavaria, Germany (E-mail: Daniel.Schmauss@gmx.de).

J Thorac Cardiovasc Surg 2013;145:1407-8

$0022-5223 / \$ 36.00$

Copyright (c) 2013 by The American Association for Thoracic Surgery

http://dx.doi.org/10.1016/j.jtcvs.2012.12.030
}

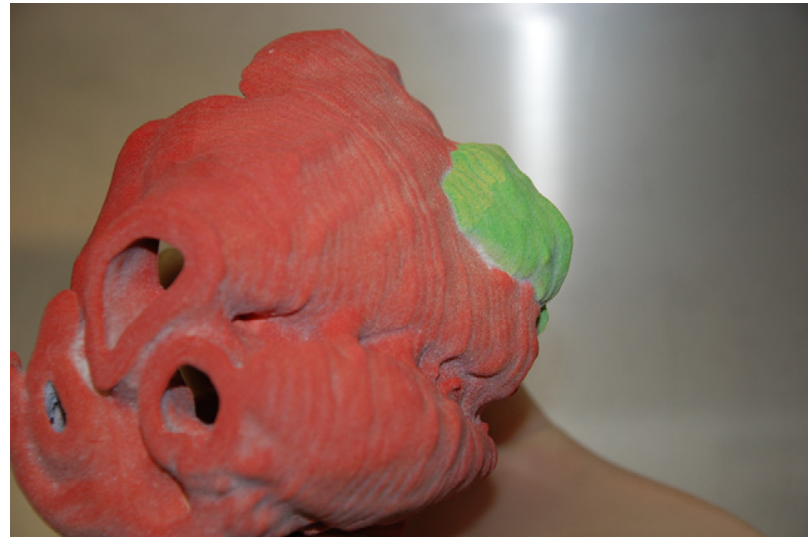

FIGURE 1. The stereolithographic model showing the heart and detailed anatomy, including the tumor on the right ventricle. The tumor is marked in a different color from the cardiac tissue because of its difference in density.

in which 3-dimensional, lifelike models can be helpful for preoperative decision making and planning of surgical procedures. The method described is practicable for

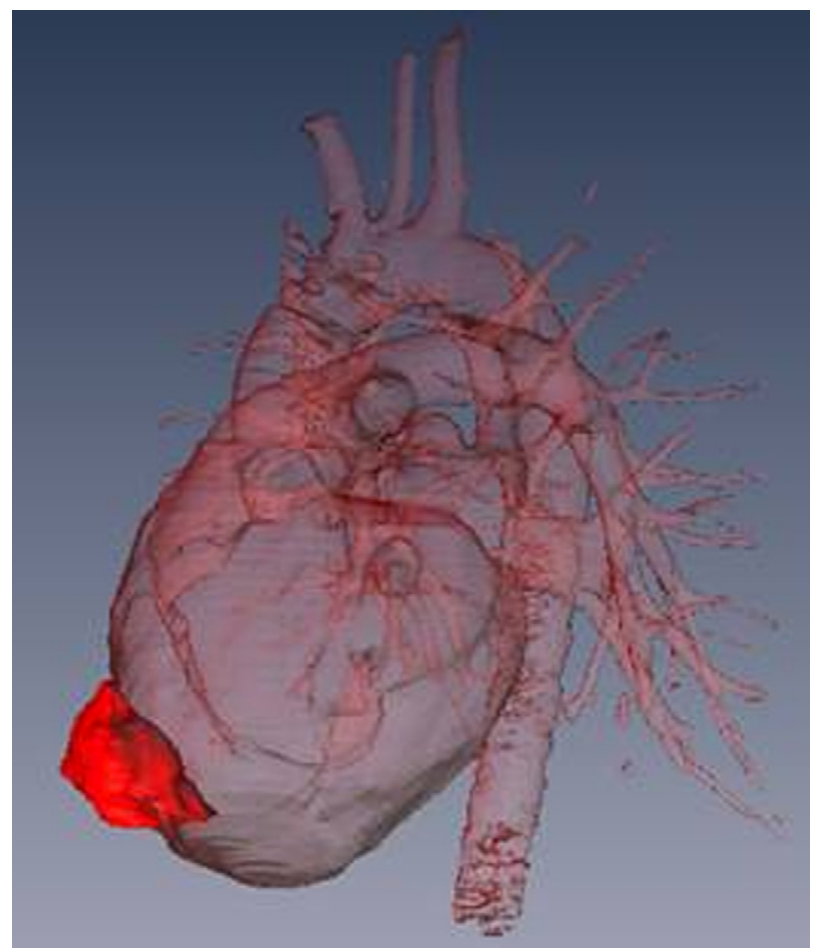

FIGURE 2. A 3-dimensional reconstruction of the heart with the tumor on the right ventricle. 


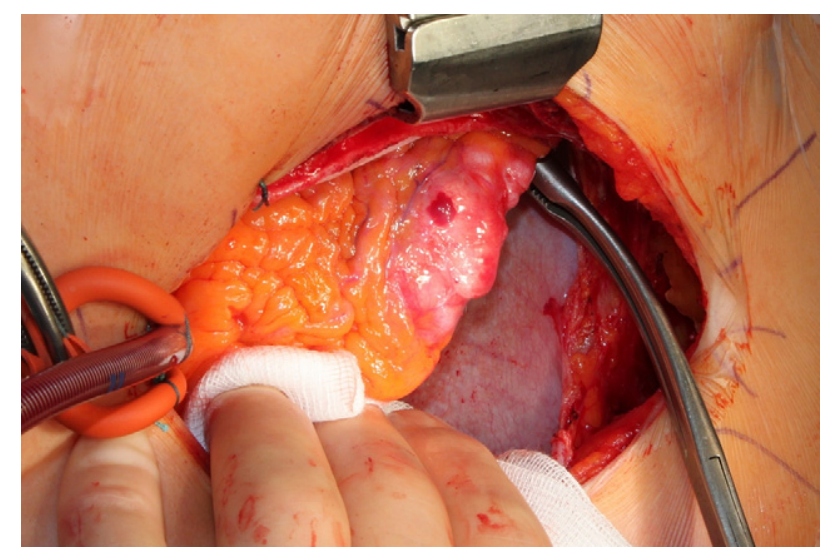

FIGURE 3. Intraoperative findings. The right ventricle can be seen with the tumor on its wall.

patients with primary cardiac tumors. It could facilitate the therapeutic decision making process by showing the exact position and infiltration of the cardiac tumor into cardiac tissue in patients in whom conventional imaging techniques such as computed tomography, magnetic resonance imaging, and echocardiography are insufficient. The system provides theoretic and practical advantages for surgeons and interventionists treating complex pathology in cardiac surgery.

\section{References}

1. Padalino MA, Basso C, Milanesi O, Vida VL, Moreolo GS, Thiene G, et al. Surgically treated primary cardiac tumors in early infancy and childhood. $J$ Thorac Cardiovasc Surg. 2005;129:1358-63.

2. Schmauss D, Schmitz C, Bigdeli AK, Weber S, Gerber N, BeirasFernandez A, et al. Three-dimensional printing of models for preoperative planning and simulation of transcatheter valve replacement. Ann Thorac Surg. 2012;93:e31-3.

3. Sodian R, Weber S, Markert M, Loeff M, Lueth T, Weis FC, et al. Pediatric cardiac transplantation: three-dimensional printing of anatomic models for surgical planning of heart transplantation in patients with univentricular heart. J Thorac Cardiovasc Surg. 2008;136:1098-9. 